\title{
Desain Media Informasi Program Studi Pada Sekolah Menengah Kejuruan (SMK)
}

\author{
Ari Apriyansa ${ }^{1}$, Rusmono ${ }^{2}$, Muhammad Yusro ${ }^{3}$ \\ 1,2,3 Universitas Negeri Jakarta \\ ${ }^{1,2,3}$ Program Studi Pendidikan Vokasional dan Keteknikan Universitas Negeri Jakarta \\ Jln. Rawamangun Muka, Jakarta Timur 13220 \\ e-mail: 19anak.rangkas@gmail.com, ${ }^{2}$ email@ rusmono.com, ${ }^{3}$ myusro@unj.ac.id
}

\begin{abstract}
Abstrak
Perubahan Spektrum Keahlian Pendidikan Menengah Kejuruan dari Permen Dikbud RI Nomor 60 Tahun 2014 menjadi keputusan Direktur Jenderal Pendidikan dan Menengah Nomor : 4678/D/KEP/MK/2016 membuat beberapa bidang jurusan di SMK berubah. Hal ini membuat masyarakat menjadi bingung karena pada keputusan tersebut memiliki banyak perubahan pada Kompetensi Keahlian. Sepktrum PSMK tahun 2016 memiliki 142 Kompetensi Keahlian yang tersebar di Indonesia, maka dengan jumlah yang banyak tersebut masyarakat akan mengalami kesulitan dalam mengetahun kompetensi keahlian yang akan dicari. Program studi Energi Terbarukan merupakan salah satu program studi yang jarang sekali diketahui masyarakat umum. Total dari program studi ini hanya ada 14 sekolah dari total 164.07 SMK di Indonesia sehingga jarang diketahui masyarakat umum dibanding dengan program studi seperti akuntansi dan pemasaran. Seiring perkembangan teknologi dibidang pendidikan yang begitu pesat, maka perlu dibentuknya media informasi khusus yang menampilkan kompetensi keahlian agar memudahkan masyarakat dalam mencari informasi dari Spektrum PSMK tahun 2016 terbaru ini. Media Informasi ini berbentuk website dengan tujuan dapat diakses melalui jaringan internet dimanapun dan kapanpun. Pengembangan penelitian ini termasuk kedalam penelitian $R \& D$ dengan menggunakan Waterfall Model atau dapat disebut juga System Development Life Cycle (SDLC) dengan tahapan pengembangan: 1. Analysis, 2. Design, 3. Implementation, 4. Testing, dan 5. Maintenance. Selain mempermudah masyarakat umum dalam mencari jurusan di SMK serta Dunia Usaha/Dunia Industri (DU/DI) juga akan terbantu dalam memenuhi formasi pegawai yang sesuai dengan kompetensi yang dibutuhkan.
\end{abstract}

Kata kunci: Sekolah Menengah Kejuruan, Spektrum PSMK 2016, Website, Media Informasi, Karir, Wirausaha.

\section{Abstract}

Changes in Spectrum of Vocational High School Education Skills from Ministry of Culture and Tourism of the Republic of Indonesia Number 60 of 2014 became the decision of the Director General of Education and Intermediary Number 4678 / D / KEP / MK / 2016 to make some majors in SMK changed. This makes people confused because the decision has a lot of changes in Skills Competencies. Sepktrum PSMK 2016 has 142 Skill Competencies spread in Indonesia, so with a large number of people will have difficulty in knowing the competence of skills to be sought. The Renewable Energy study program is one of the study programs that is rarely known to the general public. Total of this study program there are only 14 schools of total 164.07 SMK in Indonesia so rarely known to the general public compared with courses such as accounting and marketing. Along with the development of technology in the field of education is so rapid, it is necessary to establish a special information media that displays the competence of expertise in order to facilitate the public in seeking information from Spectrum PSMK this latest 2016. Media This information form of website with the aim of can be accessed through internet network wherever and whenever. The development of this research is included into $R \& D$ research by using Waterfall Model or can be called System Development Life Cycle 
(SDLC) with development stage: 1. Analysis, 2. Design, 3. Implementation, 4. Testing, dan 5. Maintenance. In addition to facilitate the general public in searching for majors in SMK and the World Business / Industrial

Keywords: Vocational School, Spectrum PSMK 2016, Website, Information Medium, Career, Entrepreneurship.

\section{Pendahuluan}

Pendidikan merupakan wadah dalam mempersiapkan Sumber Daya yang berkualitas dan memiliki kemampuan berfikir yang baik, profesional, logis, dan sistematis. Berdasarkan UUSPN nomor 20 tahun 2003 menjelaskan bahwa tujuan dari pendidikan kejuruan ialah pendidikan yang mempersiapkan peserta didik untuk dapat berkerja dalam bidang tertentu. Bidang sekolah menengah kejuruan diatur dalam keputusan Direktur Jederal Pendidikan Dasar dan Menengah Kementerian Pendidikan dan Kebudayaan Nomor: 4678/D/KEP/MK/2016 tentang Spektrum Keahlian Pendidikan Menengah Kejuruan yang dikelompokan pada 9 Bidang Kejuruan yaitu (1). Bidang Kejuruan Teknologi dan Rekayasa, (2). Bidang Kejuruan Energi dan Pertambangan, (3). Bidang Kejuruan Teknologi Informasi dan Komunikasi, (4). Bidang Kejuruan Kesehatan dan Pekerjaan Sosial, (5). Bidang Kejuruan Agribisnis dan Agroteknologi, (6). Bidang Kejuruan Kemaritiman, (7). Bidang Kejuruan Bisnis dan Manajemen, (8). Bidang Kejuruan Pariwisata, dan (9). Bidang Kejuruan Seni dan Industri Kreatif[1].

Diharapkan dengan pembagian ini Sekolah Menengah Kejuruan dapat mencetak lulusan yang berkompeten dibidangnya masing-masing. Menurut Wilkins pada tahun 2001 menyatakan "vocational is one of key factor in ensuring economicdevelopment, competitiveness and social stability in all countries, both developing and indutrialized"[2]. Pendapat tersebut mengatakan bahwa sekolah kejuruan dapat memberikan dampak positif pada sebuah negara jika dapat dikelola dengan baik.Hal ini disebabkan karena lulusan sekolah kejuruan memiliki kompetensi khusus yang dipelajari selama disekolah sehingga akan memajukan industri disuatu negara.

Perkembangan teknologi informasi yang pesat beberapa tahun kebelakang ini telah merubah paradigma masyarakat dalam mencari dan mendapatkan informasi, tidak tebatas pada informasi surat kabar, audio visual, dan elektronik tetapi juga menggunakan sumber lainnya seperti jaringan internet[3]. Perkembangan ini juga berdampak pada dunia pendidikan, teknologi dibidang pendidikan mendorong dunia pendidikan untuk berkompetitif dan terus berinovasi untuk meningkatkan kualitasnya. Salah satu inovasinya yaitu mengembangkan media informasi, media pembelajaran, dan lain sebagainnya. Salah satu teknologi yang sangat cepat dalam penyebaran informasi ialah website. Menurut Arief tahun 2011 perpendapat bahwa "Website adalah salah satu aplikasi yang berisikan dokumen-dokumen multimedia (teks, gambar, suara, animasi, video) didalamnnya yang menggunakan protokol HTTP (hypertext tansfer protokol) serta untuk mengaksesnya menggunakan perangkat lunak yang disebut dengan browser"[4]. Media informasi berbasis website merupakan media yang sangat cepat dalam proses penyebaran informasinya dibanding media informasi cetak seperti koran, majalah, dan brosur. Media informasi website dapat memberikan kontribusi yang cukup signifikan didunia pendidikan, sebagai contohnya adalah bahan ajar seperti buku paket yang biasanya dibeli atau menunggu dikirim dari dinas pendidikan pusat kesekolahsekarang cukup mengetikan judul buku dibrowserkemudian akan muncul e-book baik yang gratis maupun berbayar atau dengan dikirim melalui alamat email sehingga dapat menghemat waktu dan tenaga.

Kemajuan teknologi ini dapat juga digunakan untuk mengenalkan spektrum dari program studi pada sekolah kejuruan yang mungkin masih banyak orang yang belum mengetahuinya. Program studi Energi Terbarukan merupakan salah satu program studi yang jarang sekali diketahui masyarakat umum. Total dari program studi ini hanya ada 14 sekolah dari total 164.07 SMK di Indonesia sehingga jarang diketahui masyarakat dibanding dengan program studi seperti akuntansi dan pemasaran. Menurut Zainul Arifin angka lowongan pekerjaan masih lebih rendah dari angka pencari kerja, namun kenyataannya tidak semua lowongan pekerjaan terpenuhi 
penempatannya[5]. Sehingga dengan hal ini media informasi SMK dapat mempermudah dunia industri dalam memenuhi jumlah karyawan yang sesuai dengan bidang keahliannya dengan mengakses media informasi tersebut. Sehingga media informasi mengenai program studi SMK perlu dibangun untuk ikut serta membantu mensosialisasikan Spektrum Terbaru SMK tahun 2016 kepada masyarakat serta dunia industri.

\section{Metode Penelitian}

Pengembangan media informasi program studi SMK dilakukan dalam beberapa tahap agar mempermudah proses pengembangan media informasi. Metode yang digunakan pada penelitian ini menggunakan konsep Waterfall Model atau dapat disebut juga dengan System Development Life Cycle (SDLC). Tahapan pengembangan media informasi sekolah mengengah kejuruan disajikan pada gambar 1 dibawah ini.

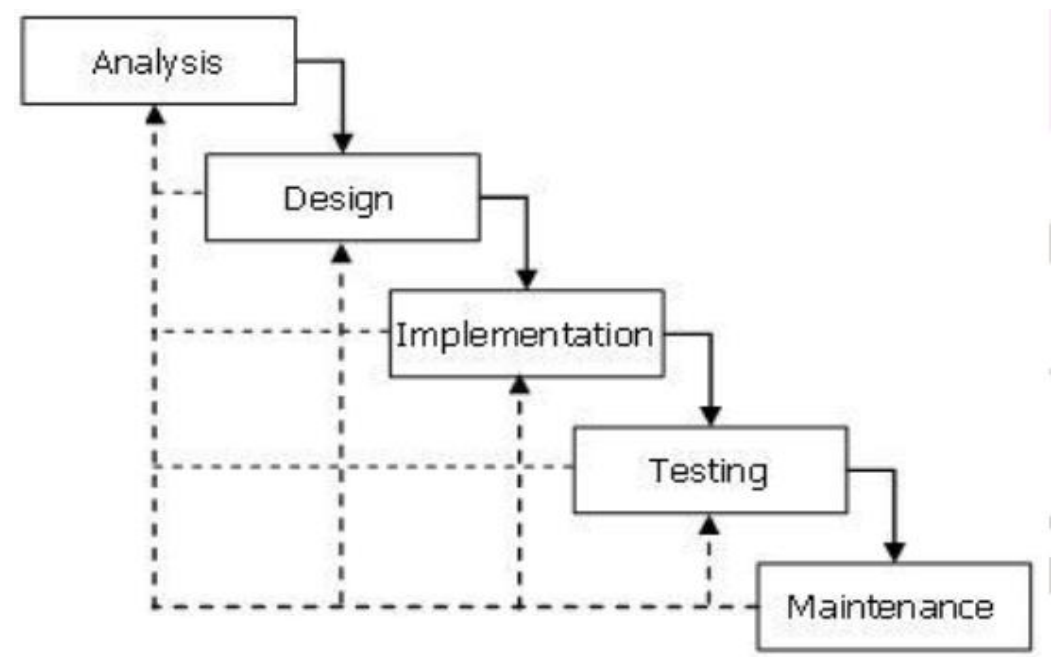

Gambar 1. Waterfall Model[6]

Penjelasan proses dari masing-masing tahapan tersebut adalah sebagai berikut ini:

1. Analysis

Tahap analysis merupakan dasar atau pondasi dari perencanaan project dalam menentukan apa saja yang harus dipersiapkan dengan cara observasi kebeberapa sekolah di Provinsi Banten dan DKI Jakarta, wawancara dengan beberapa guru dan siswa, serta studi pustaka dari jurnal nasional maupun internasional agar pengembangan suatu media informasi dapat terlakasana dengan baik. Tujuan dari tahap analysisa dalah untuk mengumpulkan data yang sudah diklasifikasi sesuai kebutuhan.

2. Design

Penyusunan deskripsi struktur bentuk software yang akan dirancang untuk pengembangan software itu sendiri sehingga terbentuk seketsa atau pengaturan dari beberapa elemen yang terpisah kedalam satu kesatuan yang utuh dan berfungsi. Didalamnya terdapat konfigurasi komponen yang saling terhubung dalam diagram. Tahap desgin media informasi terdiri atas Rancang Diagram, Data Flow Diagram (DFD), Entity Relationship Diagram (ERD), serta Perancangan Interface.

\section{Implementation}

Semua element dari tahap desain dan aktivitas sistem disatukan sehingga terbentuk sebuah sistem yang saling terhubung dalam satu aplikasi berupa prototipe yang dapat dijalankan. Hasil dari desain dibuat sesuai dengan perancangan interface. 
4. $\quad$ Testing

Pengujian sistem aplikasi dari segi user atau calon pengguna website dan admindengan menggunakan beberapa browser yang berbeda - beda. Tahap testing media informasi yaitu pengujian input-output serta pengujian menggunakan berbagai web-browser dan device.

5. Maintenance

Tahapan maintenance berarti dukungan teknis terhadap sistem yang sudah jadi dan dilakukan oleh tim yang memahami sistem serta dapat menjawab atau memberikan solusi terhadap permasalahan yang terjadi.

Proses dari masing-masing

2.1 Pengumpulan Data

Pengumpulan data utama diambil dengan cara studi pustaka, wawancara, serta observasi. Data ini kemudian diklasifikasi seperti berikut ini:

a. Data Bidang Keahlian

b. Data Program Keahlian, dan Kompetensi Keahlian

c. Data Lama Studi Kompetensi Keahlian

d. Data Kompetensi Inti dan Kompetensi Dasar

e. Data Karir per Program Keahlian

f. Data Program Studi Liner Jurusan

g. Data Berita Penunjang

\subsection{Perancangan Sistem}

Proses perancangan media informasi dibuat menggunakan Rancang Diagram,Data Flow Diagram(DFD), dan Entity Relationship Diagram (ERD)

a. Racangan Diagram Aplikasi Website

Tampilan Rancangan Diagram website media informasi Program Studi Sekolah Menengah Kejuruan dapat dilihat pada gambar 2

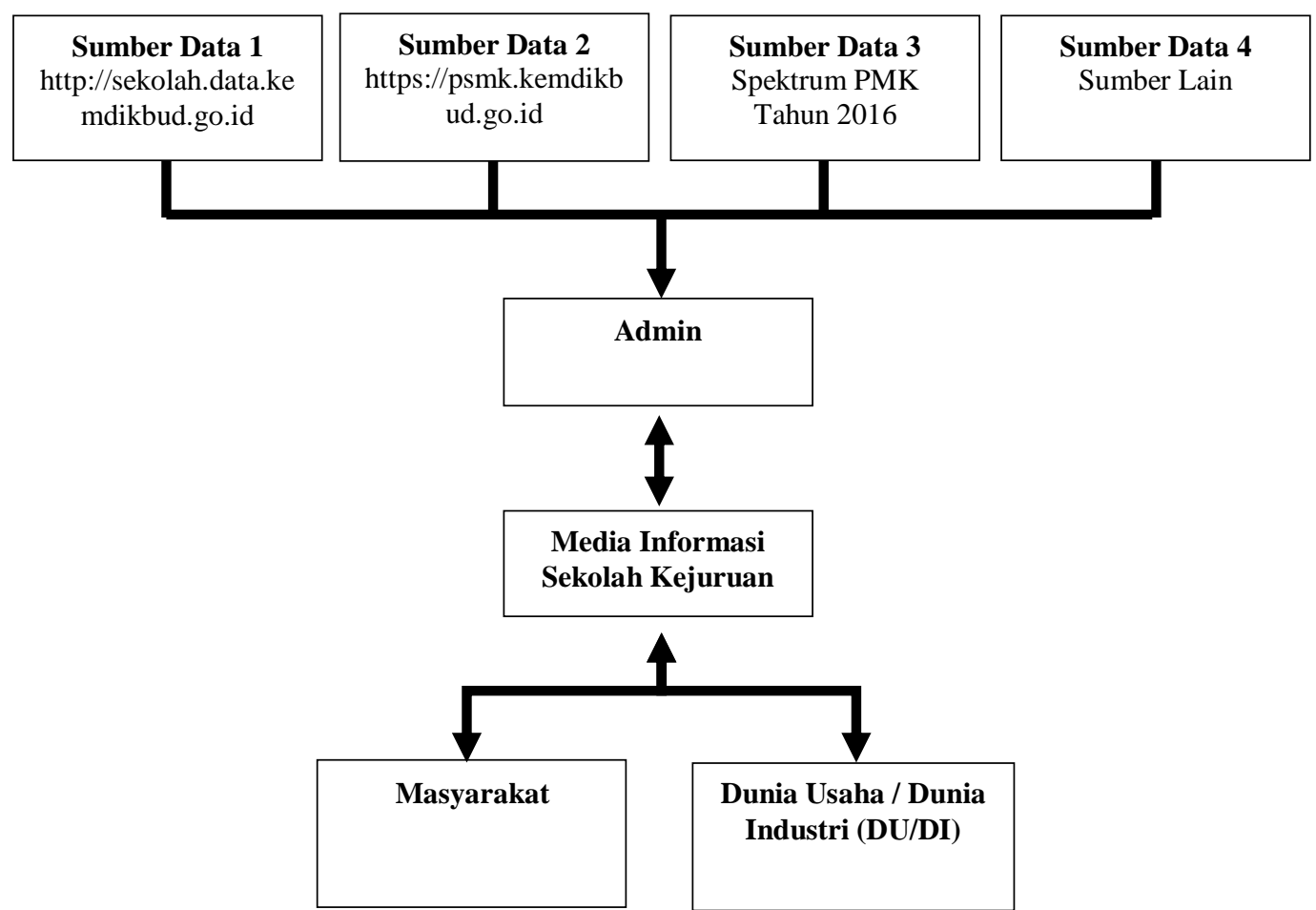

Gambar 2. Rancangan Diagram Wesbite Media Informasi Prodi SMK 
b. Data Flow Diagram level 0 (DFD level 0)

Media informasi mendefinisikan analisis kebutuhan apa saja secara detail menggunakan bentuk Data Flow Diagram level 0 (DFD level 0)[7]. Pada DFD level 0 media informasi sekolah kejuruan memiliki 2 entitas eksternal (admin, masyarakat dan DU/DI) yang menjadi asal data dan tujuan data. Terdapat 8 data utama pada aliran data yang berjalan dari proses menuju entitas eksternal dan sebaliknya. Sistem Informasi Sekolah Mengah Kejuruan menjadi pusat proses pengelolaan dan transformasi data. Tampilan DFD level 0 Website Media Informasi Sekolah Menengah Kejuruan ditunjukan pada gambar 3.

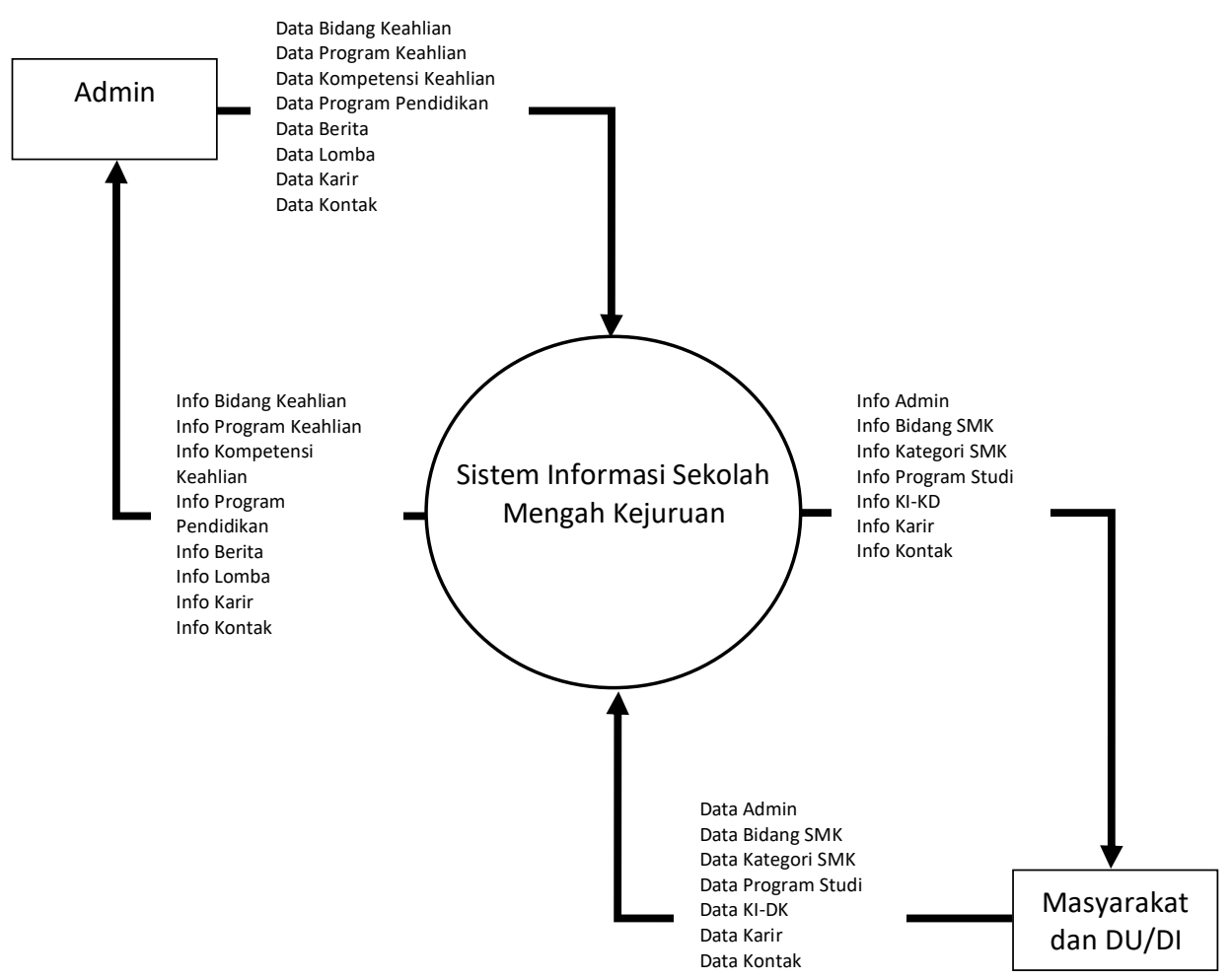

Gambar 3. Rancangan DFD level 0 Website Media Informasi Prodi SMK

c. Entity Relationship Diagram (ERD)

Desain model konseptual hubungan antara penyimpanan pada media informasi dideskripsikan menggunakan desai Entity Relationship Diagram (ERD)[8]. Tampilan Entity Relationship Diagram Website Media Informasi Program Studi Sekolah Menengah Kejuruan ditunjukan pada gambar 4. 


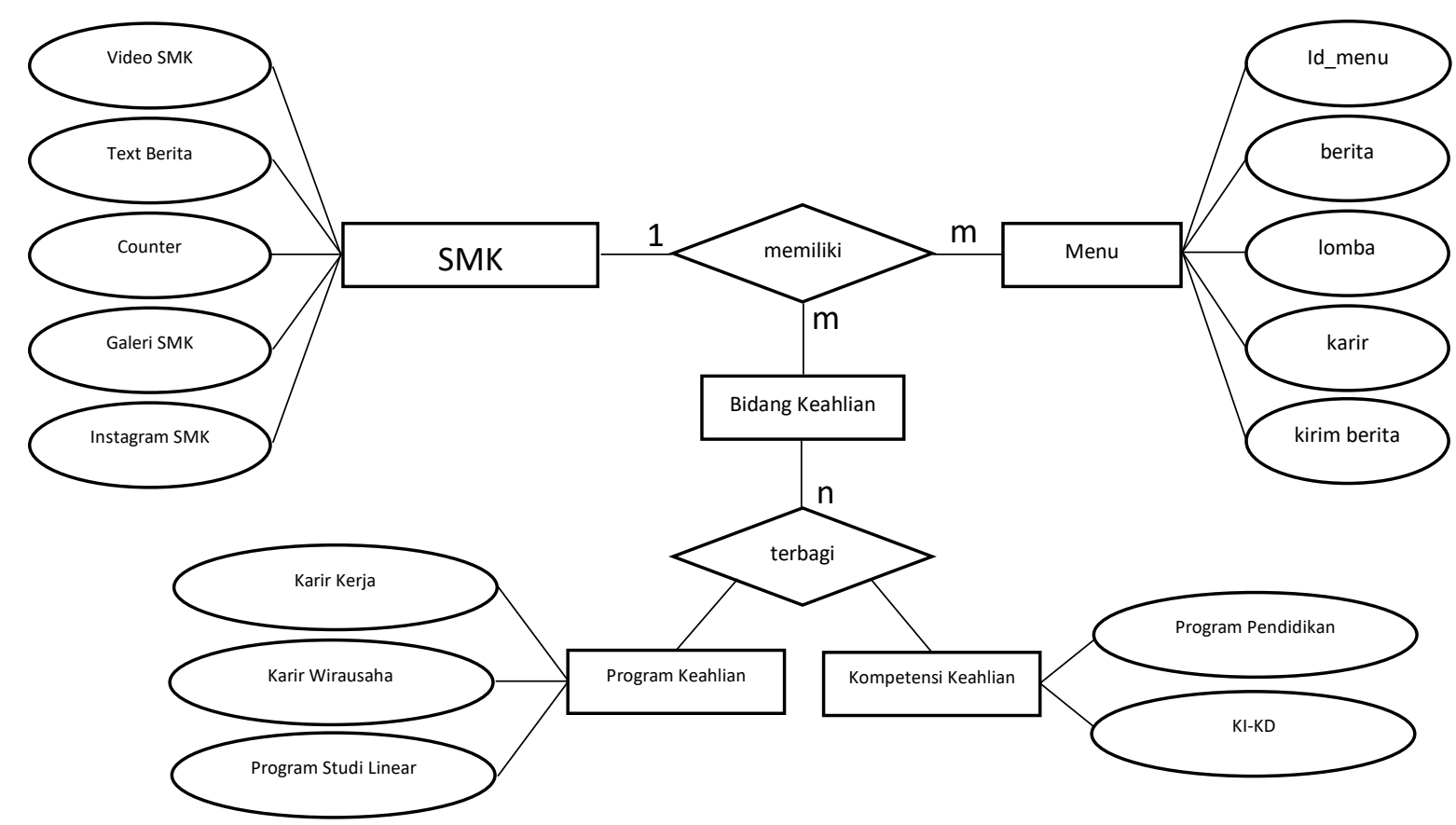

Gambar 4. Entity Relationship Diagram Website Media Informasi Program Studi

\subsection{Perancangan Antarmuka}

Tahap perancangan antarmuka (interface) Website Media Informasi Program Studi Sekolah Menengah Kejuruan terdiri dari perancangan input dan output. Perancangan ini berfungsi untuk memudahkan pembaca dalam memahami isi dan konten dari website[9][10]. Tampilan perancangan interface media informasi sekolah kejuruan dapat dilihat pada tabel 1.

Tabel 1. Perancangan Interface Media Informasi Sekolah Kejuruan

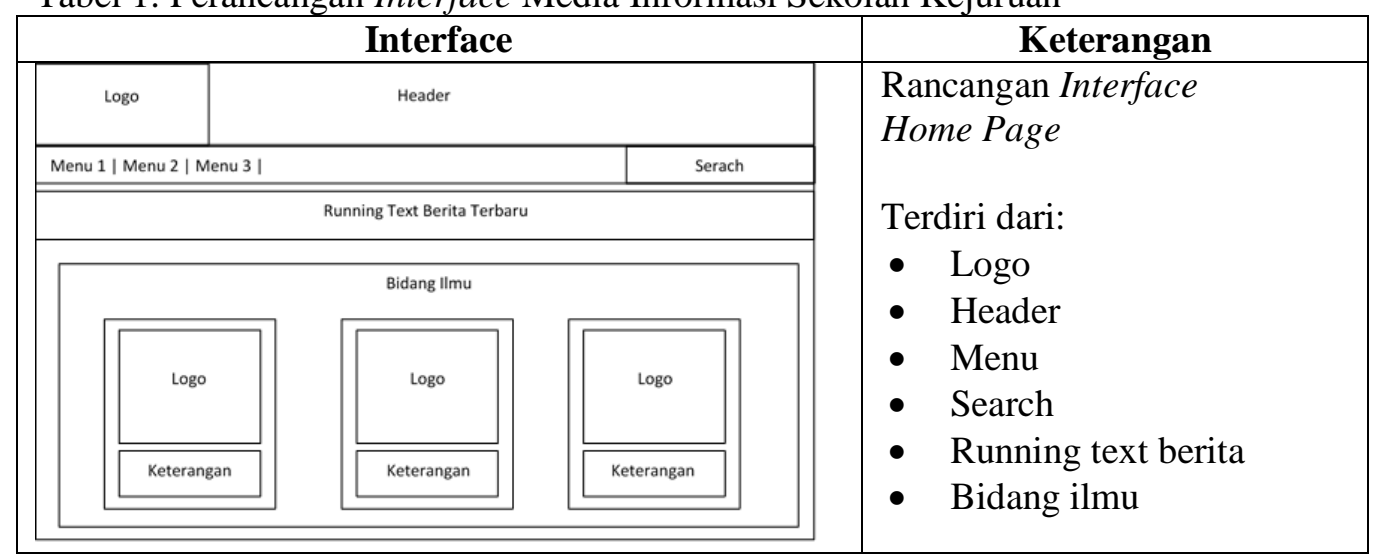




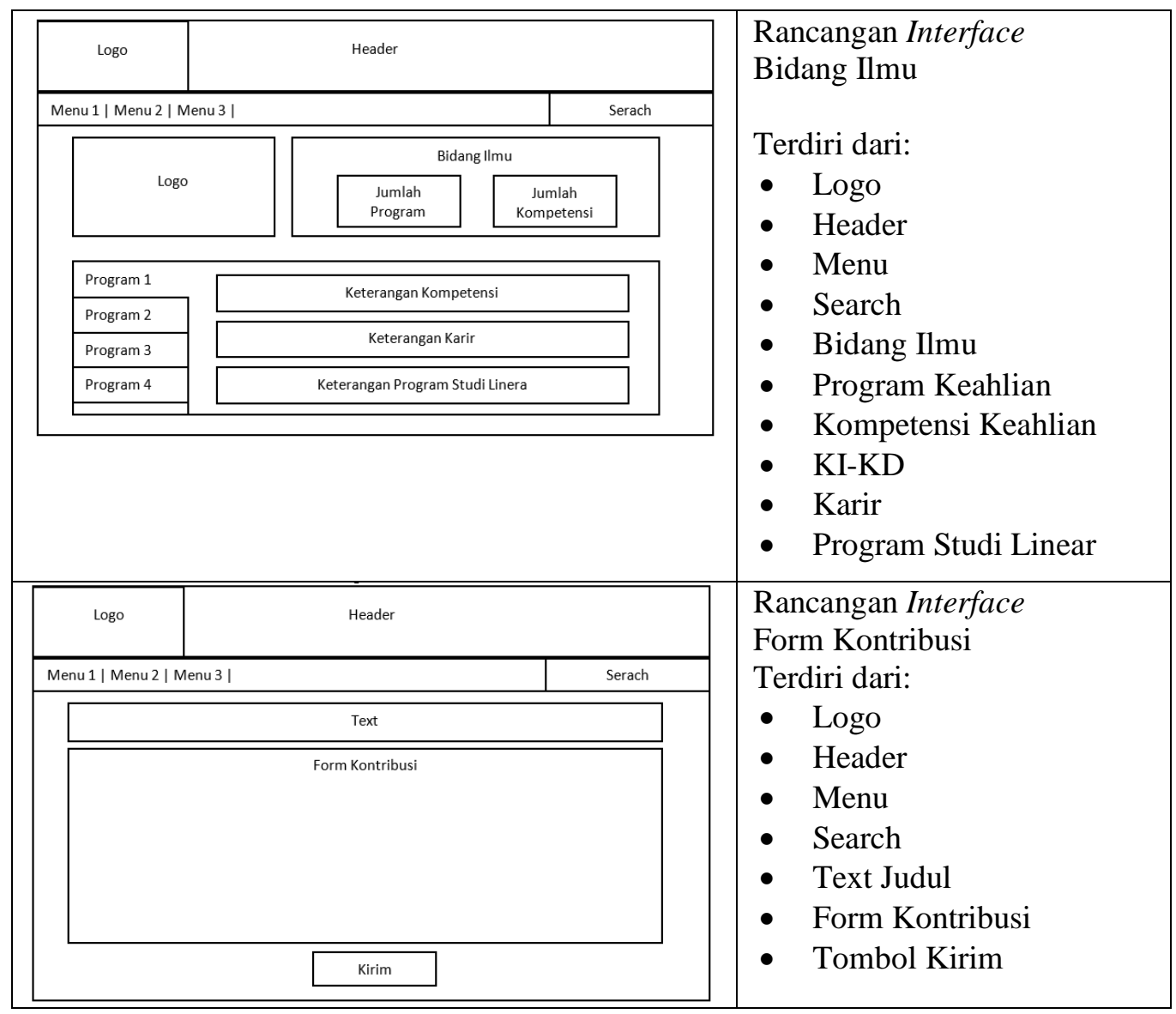

\section{Hasil dan Pembahasan}

\subsection{Pembahasan}

Media Informasi Program Studi SMK yang dirancangan diuji terlebih dahulu disetiap halaman guna mengetahui apakah sudah berfungsi melalui link http://smklebak.com. Tahap pengujian ini dilakukan terhadap media informasi menggunakan teknik black-box testing melalui pengujian input dan output serta pengujian menggunakan web browser menggunakan berbagai device[11]. Tujuannya adalah untuk mengetahui apakah fungsi input dan output dari media informasi telah berjalan dengan baik serta dapat mengetahui apakah media tersebut mendukung webbrowser dan perangkat lainnya.

Tabel 2. Tampilan Media Informasi Sekolah Kejuruan

\begin{tabular}{|l|l|}
\hline Tampilan & Keterangan \\
\hline Tampilan Home Page \\
Tampilan home page \\
memiliki backgroud putih \\
dan tulisan dominasi hitam \\
agar jelas dibaca. Terdapat \\
menu utama dan bidang ilmu \\
yang dilengkapi logo untuk \\
memudahkan pengguna \\
dalam mencari program studi \\
yang dituju.
\end{tabular}




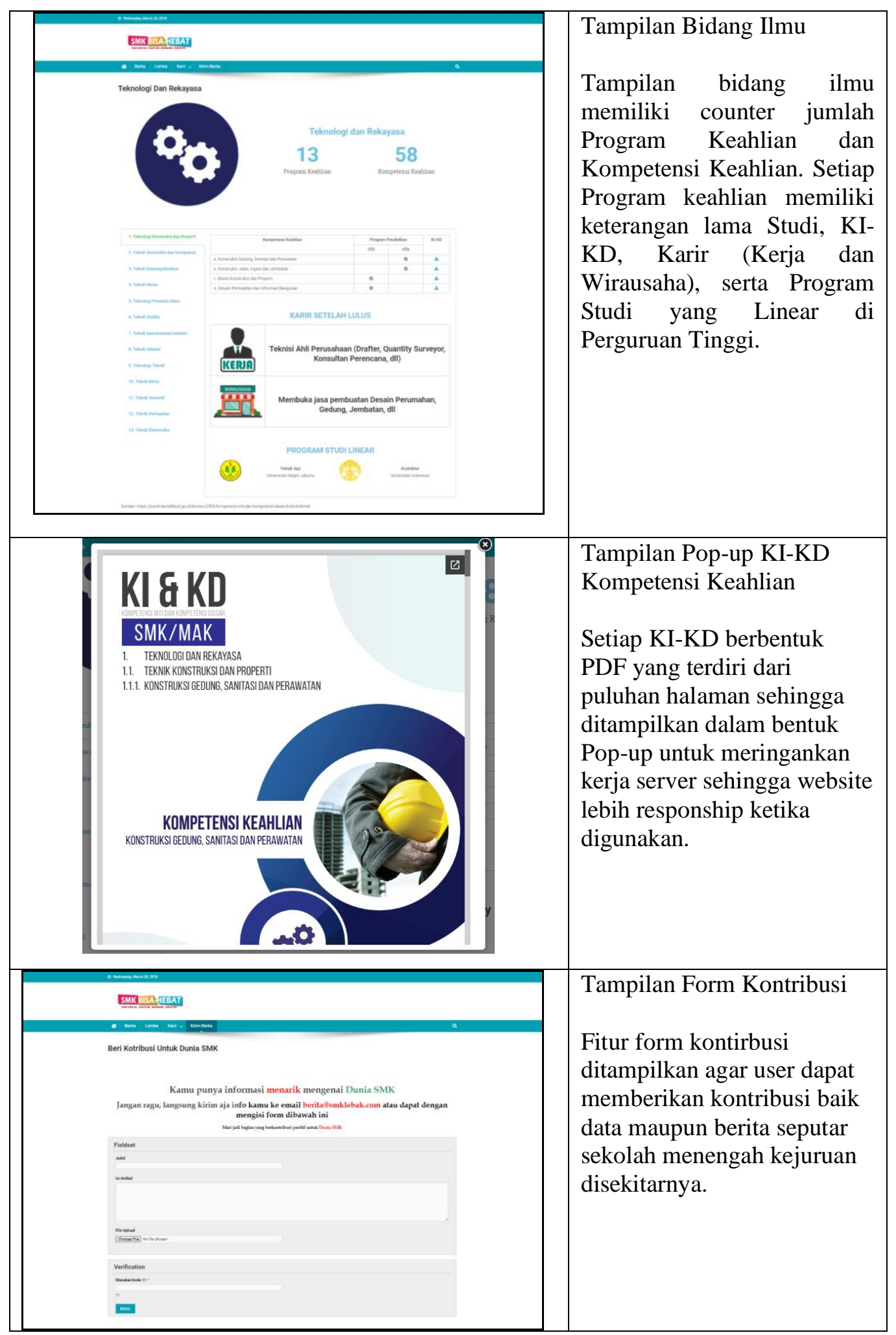




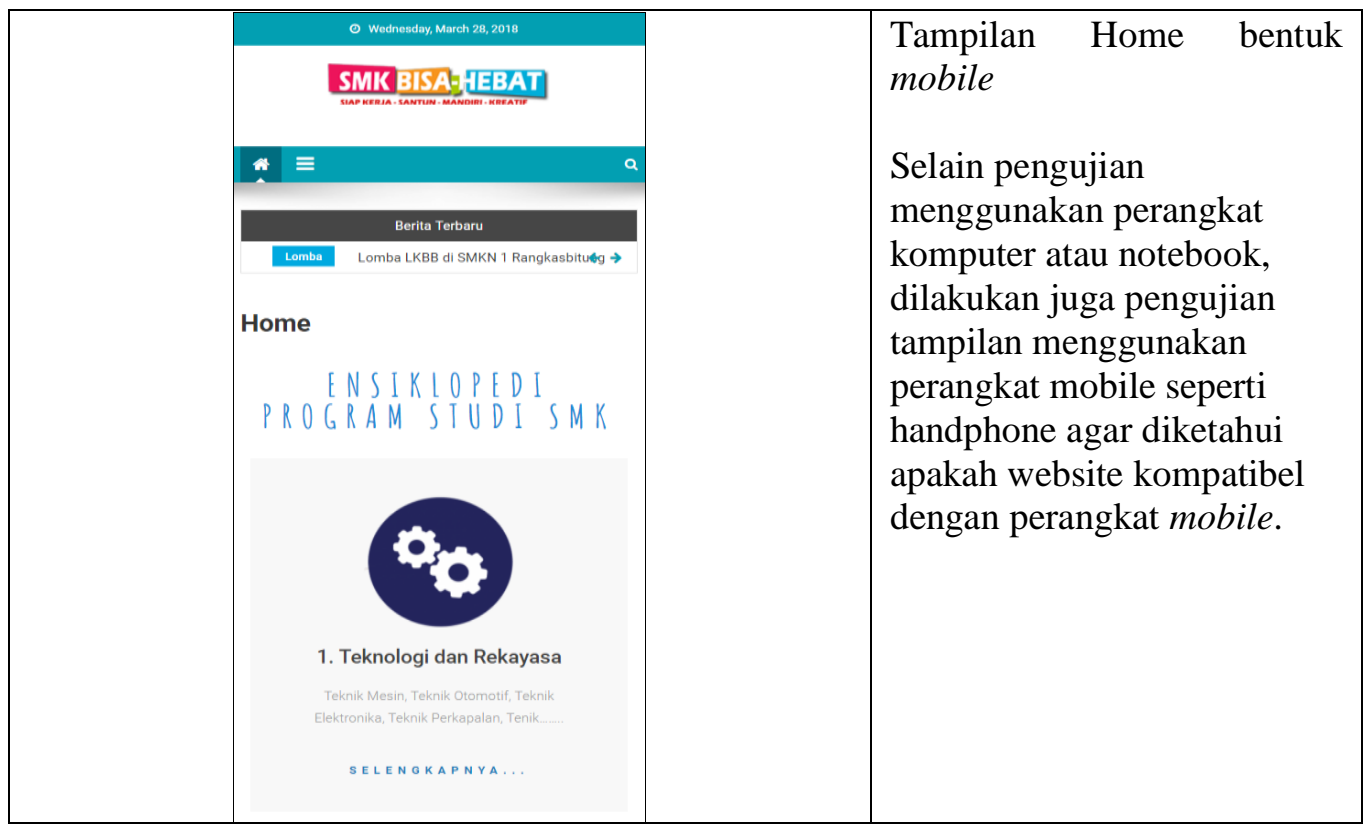

a. Pengujian Data Input dan Output Media

Tabel 3. Pengujian Input dan Output Media[12]

\begin{tabular}{|c|c|c|c|}
\hline \multirow{2}{*}{ No } & \multirow{2}{*}{ Pengujian } & \multicolumn{2}{|c|}{ Hasil } \\
\hline & & Berhasil & Gagal \\
\hline \multicolumn{2}{|c|}{ A.Input } & $\checkmark$ & - \\
\hline 1. & Data Menu & $\checkmark$ & - \\
\hline 2. & Data Berita & $\checkmark$ & - \\
\hline 3. & Data 9 Bidang Keahlian Spektrum 2016 & $\checkmark$ & - \\
\hline 4. & Data 48 Program Keahlian & $\checkmark$ & - \\
\hline 5. & Data 142 Kompetensi Keahlian & $\sqrt{ }$ & - \\
\hline 6. & Data Lama Program Keahlian (Tahun) & $\checkmark$ & - \\
\hline 7. & Data 142 KI-KD Kompetensi Keahlian & $\checkmark$ & - \\
\hline 8. & Data Prospek Kerja dan Wirausaha & $\checkmark$ & - \\
\hline 9. & Data Program Studi Linear di Perguruan Tinggi & $\checkmark$ & - \\
\hline \multicolumn{4}{|c|}{ B. Output } \\
\hline 1. & Lihat data Menu & $\checkmark$ & - \\
\hline 2. & Lihat Berita & $\checkmark$ & - \\
\hline 3. & Lihat Bidang Keahlian & $\checkmark$ & - \\
\hline 4. & Lihat Program Keahlian & $\checkmark$ & - \\
\hline 5. & Lihat Kompetensi Keahlian & $\checkmark$ & - \\
\hline 6. & Lihat Lama Program Keahlian & $\checkmark$ & - \\
\hline 7. & Lihat KI-KD & $\checkmark$ & - \\
\hline 8. & Lihat Karir Stelah Lulus & $\checkmark$ & - \\
\hline 9. & Lihat Program Studi Linear di Perguruan Tinggi & $\checkmark$ & - \\
\hline
\end{tabular}

Pada tahap pengujian data input dan output pada media informasi dapat dijalankan dengan baik tanpa terdapat kendala yang berarti. Sehingga dapat dikatakan bahwa pengujian tahapinput dan output media telah berhasil serta sukses dijalankan. 
b. Pengujian Pada Web Browser

Tabel 4. Pengujian menggunakan web browser

\begin{tabular}{|l|l|c|c|c|}
\hline No & \multicolumn{1}{|c|}{ Browser } & Versi & Hasil & Keterangan \\
\hline 1. & Google Chrome & 65.0 .3325 .181 & Berhasil & $\begin{array}{c}\text { Aplikasi dapat berjalan } \\
\text { dengan baik. }\end{array}$ \\
\hline 2. & Opera & 51.0 .2830 .55 & Berhasil & $\begin{array}{c}\text { Aplikasi dapat berjalan } \\
\text { dengan baik. }\end{array}$ \\
\hline 3. & Mozilla Firefox & 59.0 .2 & Berhasil & $\begin{array}{c}\text { Aplikasi dapat berjalan } \\
\text { dengan baik. }\end{array}$ \\
\hline 4. & $\begin{array}{l}\text { Browser Xiaomi } \\
\text { mi max }\end{array}$ & $\begin{array}{c}\text { Xiaomi Browser } \\
\text { V.9.2.8 } \\
\text { Marshmallow } \\
6.0 .1\end{array}$ & Berhasil & $\begin{array}{c}\text { Aplikasi dapat berjalan } \\
\text { dengan baik. }\end{array}$ \\
\hline 5. & $\begin{array}{l}\text { Browser Asus } \\
\text { Zenfone 2 Laser }\end{array}$ & $\begin{array}{c}\text { Asus Browser } \\
\text { V2.1.2.83 } \\
\text { Lollipop 5.0.2 }\end{array}$ & Berhasil & Aplikasi dapat berjalan \\
dengan baik.
\end{tabular}

Pengujian dilakukan menggunakan 6 jenis web browser dengan berbagai jenis device.

c. Hasil Pengujian

Berdasarkan hasil pengujian pada media informasi maka dapat disimpulkan bahwa:

1. Pada tabel 1 dilakukan pengujian input-output dan semua fitur berhasil dijalankan dengan baik.

2. Pada tabel 2 dilakukan pengujian menggunakan berbagai browser dan perangkat yang diakses secara online berjalan dengan baik. Perngkat PC menggunakan browser Google Chrome Versi 65.0.3325.181, Opera Versi 51.0.2830.55, dan Mozilla Firefox Versi 59.0.2. Selain itu pengujian dilakukan dengan perangkat smartphone Xiaomi MI Max (Xiaomi Browser V.9.2.8 Marshmallow 6.0.1), Asus Zenfone 2 Laser (Asus Browser V2.1.2.83 Lollipop 5.0.2), dan iPhone 6 Plus (Safari Browser V5.1.10 iOS 11.2.6). Semua browser dan perangkat dapat berkerja dengan baik dan sebagai mana mestinya.

\subsection{Hasil dan Pembahasan}

Hasil dari penelitian ini adalah terbangunnya Media Informasi mengenai Sekolah Menengah Kejuruan di Indonesia sesuai dengan Spektruk SMK terbaru tahun 2016. Bidang keahlian Sekolah Mengengah Kejurua merupakan menu utama yang ditampilkan dalam 9 bidang keahlian. Setiap bidang dibagi lagi kedalam beberapa Program dan Kompetensi Keahlian. Setiap kompetensi keahlian dilengkapi dengan masa studi dan Kompetensi Inti serta Kompetensi Dasar (KI-KD) yang dikemas dengan tampilan popup yang meringankan akses media informasi sehingga mempermudah pengunjung dalam menggunakan media informasi ini. Selain itu disetiap program keahlian terdapat kolom karir dan kolom program studi Perguruan Tinggi yang linear sehingga pengunjung dapat mengetahui prospek kedepan dari program keahlian tersebut.Pengunjung juga dapat memberikan kontribusi atau masukan berupa berita, artikel, dan informasi lainnya melalui form yang tersediapada halaman kontribusi. 


\section{Kesimpulan}

Penelitian ini merupakan penelitian dan pengembangan (R\&D) menggunakan model pengembanganWaterfall Model atau dapat disebut juga dengan System Development Life Cycle (SDLC) yang terdiri dari 5 tahapan yakni: Analysis, Design, Implementation, Testing, dan Maintenance. Pada tahap analysis dilakukan klasifikasi data dari hasil studi pustaka, wawancara, dan obeservasi. Tahap design dibuat blok diagram, DFD level 0, ERD dan didesain bentuk interfacenya sesuai kebutuhan. Tahap Implementasi dibuat halaman sesuai dengan desain interface sebelumnya. Tahap selanjutnya menguji input-output media serta mengakses fitur media dengan berbagai web browser dan device. Tahap terakhir ialah maintenance dimana media informasi dijaga dengan baik agar terlindungi dari pengguna yang tidak bertanggung jawab malalui security sistem di hosting.

Media informasi program studi SMK ini memberikan informasi mengenai bidang bidang ilmu, program keahlian, kompetensi keahlian, kurikulum, karir setelah lulus SMK, serta program studi yang linear ditingkat Perguruan Tinggi. Sehingga masyarakat dapat mengetahui mengenai keberagaman program studi di SMK dan pihak Dunia Usaha / Dunia Industri (DU/DI) dapat memenuhi pegawai sesuai dengan kompetensi yang dibutuhkan.

\section{Daftar Pustaka}

[1] K. D. J. P. D. dan M. K. P. dan Kebudayaan, Spektrum PMK Tahun 2016. 2016.

[2] I. Hanafi, "Re-Orientasi Keterampilan Kerja Re-Orientasi Keterampilan Kerja," $J$. Pendidik. Vokasi, vol. 2, hal. 107-116, 2012.

[3] M. Husni, "Pemanfaatan Teknologi Informasi Dalam Bidang Pendidikan (E-education)," J. Mikrotik, vol. 2, no. 1, hal. 1-5, 2014.

[4] G. W. \& W. E. Susanto, "Perancangan Website Sebagai Media Informasi dan Promosi Batik Khas Kabupaten Kulonprogo," J. Khasanah Ilmu, vol. 6, no. 2, hal. 46-55, 2015.

[5] A. Apriyansa, "Pengembangan Pendidikan Karakter Di Sekolah Kejuruan," in Prosiding Seminar Nasional Pendidikan Vokasional (SNPV), 2017, hal. 108-112.

[6] Nurasiah, "Perencanaan Pengembangan Sistem Informasi Pembayaran Uang Kuliah Dengan Metode SDLC Waterfall," J. Teknol. dan Rekayasa, vol. 19, no. 3, hal. 72-81, 2014.

[7] Ermatita, “Analisis dan Perancangan Sistem Informasi Perpustakaan,” J. Sist. Inf., vol. 8, no. 2355-4614, hal. 966-977, 2016.

[8] F. Muttaqin, M. Al Musadieq, dan Riyadi, "Analisis dan Desain Sistem Informasi Berbasis Komputer untuk Persediaan Barang pada Tokoh Bahan Bangunan (Studi kasus pada UD . Sumber Bumi Subur )," J. Adm. Bisnis, vol. 8, no. 1, hal. 1-7, 2014.

[9] E. P. A. Akhmad, "Pengembangan Sistem Informasi Akademik Berbasis Web di Jurusan Ketatalaksanaan Pelayaran Niaga Program Diploma Pelayaran Universitas Hang Tuah Surabaya," J. Apl. Pelayaran dan Kepelabuhan, vol. 7, no. 1, hal. 1-20, 2016.

[10] T. Yumoto, T. Matsuodani, dan K. Tsuda, "A test analysis method for black box testing using AUT and fault knowledge," Procedia Comput. Sci., vol. 22, hal. 551-560, 2013.

[11] M. S. Mustaqbal, R. F. Firdaus, dan H. Rahmadi, "Pengujian Aplikasi Menggunakan Black Box Testing Boundary Value Analysis (Studi Kasus : Aplikasi Prediksi Kelulusan SNMPTN)," J. Ilm. Teknol. Inf. Terap., vol. 1, no. 3, hal. 31-36, 2015.

[12] K. Suhada, Danuri, dan F. Profesio Putra, "Aplikasi web promosi kuliner dan rumah makan online," J. Teknol. Inf. Komun. Digit. Zo., vol. 8, no. 1, hal. 25-33, 2017. 